\title{
EXPERIMENTAL AND NUMERICAL INVESTIGATION ON THE TENSILE AND WATER ABSORPTION BEHAVIOR OF JUTE/CARBON REINFORCED EPOXY COMPOSITE
}

\author{
Abu Shaid Sujon, Nagib Mehfuz, Mohammad Ahsan Habib \\ Islamic University of Technology, Department of Mechanical and Production Engineering, \\ Board Bazar Gazipur -1704, Bangladesh
}

\begin{abstract}
Now a days traditional metallic and alloy material are replaced with the fiber based composite material in numerous engineering application. The effect of stacking sequence on tensile and flexural properties of epoxy-based carbon and jute fiber composites has been investigated experimentally and numerically in this paper. Six layers of woven unidirectional jute fiber and four-layer of carbon fiber has been fabricated by vacuum assisted resin infusion process with five different stacking sequences. The tensile and water absorption behaviors of the prepared composite samples were experimentally studied as per the standard of ASTM. The obtained results from the experiments revealed that the stacking sequence of the fiber has a great effect on the tensile and water absorption properties of the composite. To validate the experimental result of the tensile test, the exact $3 \mathrm{D}$ model of the composite laminates were imported to a Finite Element Analysis (FEA) software with the exact experimental condition. The predicted FEA results were compared with the experimental results and a good similarity between them has been observed.
\end{abstract}

Keywords: Stacking sequences, Hybrid laminates, Jute fiber, Carbon fiber, Mechanical properties, Finite element analysis.

Cite this Article: Abu Shaid Sujon, Nagib Mehfuz, Mohammad Ahsan Habib, Experimental and Numerical Investigation on the Tensile and Water Absorption Behavior of Jute/Carbon Reinforced Epoxy Composite. International Journal of Mechanical Engineering and Technology 11(2), 2020, pp. 130-140.

https://iaeme.com/Home/issue/IJMET?Volume=11\&Issue=2

\section{INTRODUCTION}

Environmental regulation, along with the consumer demand for the eco-friendly and recyclable material a trend has been observed in using natural fibers as a replacement for nonrecyclable synthetic fibers like glass, Kevlar and carbon fiber [1].Due to their enhanced and superior characteristics than their respective individual fiber component, there has been an 
increased focus in hybrid composite material in recent years[2], [3]. Hybrid composites are manufactured with the help of a matrix by mixing two or more distinct strengthening material. In this way, a new composite material with high mechanical properties is manufactured[4]. Carbon fiber, because of its inferior features like strong mechanical strength, elasticity, low density, and excellent fire resistance, is widely used as reinforcement materials [5]. Due to these reasons, in many areas of engineering technology, as for example automotive industry, aviation industry, ship building industry, construction, and sporting equipment, it makes carbon fiber irreplaceable. However, because of the brittleness of carbon fibers, carbon fiber composites are more likely to be affected by the stress-concentration in real-life application [6].

Furthermore, the manufacturing of carbon fiber is expensive. The only way to increase the strength of CFRPs is for some layers of carbon fiber to be replaced by ductile fibers. This is known as hybridization that can contribute and therefore produce good material which is costeffective and eco-friendly. In a hybrid composite laminate, Park and Jang [6] integrated plastic fiber polyethylene (PE) to create a hybrid composite laminate. Due to its high elongation at break and high specific strength and rigidity, they used PE fiber. They found that, when the carbon fiber was placed at the outer layer, the hybrid composite demonstrated the greatest flexural strength.

Natural fibers are generally treated with physical and chemical solutions to improve interaction with thermoplastic or thermoset matrices to eliminate mineral, pectin, and waxes to create robust bonding, which gives better mechanical properties [7]. However, weak binding is also helpful to enable debonding and fiber pull-out, which is difficult in composite laminate processes [8]. From the literature review, it has been found out that the treatment of natural fibers may also significantly reduce the mechanical characteristics [9] of composites as well as lower the damping magnitude [10]. Hence, the fibers used for this research were not further treated, and the fibers were used as they were fabricated.

A significant number of researchers have concentrated on hybrid composites comprising of organic fiber (flax, jute, sisal) and synthetic fibers (carbon and glass) to reduce the price and weight of composite laminates as well as to increase impact and damage resistance [11][13]]. Ramesh [14] produced composites reinforced with sisal/glass and jute/glass and evaluated their tensile strength and flexural strength. They study composites with sisal fibers that have higher tensile strength than composites with jute fibers, while both have less strength than glass composites. Dhakal [1] evaluated the thermal stability, tensile, and flexural characteristics of composites made of carbon, flax, and flax/carbon. Results showed that mixed flax/carbon fiber composites had an improvement in elongation at break relative to plain carbon composites. But, due to their inherently lower strength, the addition of flax fibers reduced the flexural strength of carbon composites. In recent time, several researchers explored the impact of fiber stacking sequences on mechanical properties of composites material. Velu and Srinivasan [15] intended to determine the weight and mechanical characteristics of the jute (J)/glass (G) composites (JJGG, JGJG, GGJJ) using distinct lay-up configurations. They reported that when the stacking sequence was GGJJ, tensile and flexural strength was the highest. Gujjala [16] designed and examined four different types of jute/glass composites. Their findings showed that the combination of JGJG and GJJG had the greatest flexural and tensile strength, respectively. Zhang [17] examined the impact of stacking sequence on the tensile property of glass $(\mathrm{G}) /$ flax $(\mathrm{F})$ composite. Their stacking sequences were $[\mathrm{GF}] \mathrm{s}$, [GGFF] s, and [GGGGFFFF] s. Owing to more contact and distinct phases between flax and glass layers, $[\mathrm{GF}] \mathrm{s}$ laminate had the maximum tensile resistance and failure strain. 
It can be noticed that previous researchers have found that carbon-jute hybrid composites can replace carbon fiber rein- forced polymer (CFRP) composites without significant loss in mechanical properties and with improved damping properties.

Jute fiber is one of the most promising materials for the production of Hybrid composite in recent years. Jute fiber is an outstanding fiber that can be hybridized with synthetic fibers such as carbon, glass, or aramid to generate a composite material with desirable impact characteristics for a wide range of applications. Jute fiber is an organic fiber which has good strength, eco-friendly, inexpensive, recognized for their damping properties as well as possessing moderate impact resistance over other natural fibers. Synthetic fiber, such as carbon fibers, could be used for hybridization to further improve the tensile, flexural, and impact properties of jute fibers.

In this work, interplay hybrid composites were prepared with jute fiber and carbon fiber as reinforcement and epoxy resin as a matrix. The objective of this study was to investigate the effect of different stacking sequences of fiber layers on the overall mechanical properties of the hybrid composite.

\section{MATERIALS AND METHODOLOGY}

\subsection{Constituents}

Jute is a natural fiber which abundantly available in Bangladesh and at the time it is low cost, eco-friendly, versatile in textile fields with a moderate mechanical property. Due to these reasons jute fiber has potential to replace synthetic fibers in the field of composite material. In this research work unidirectional woven jute fiber fabrics (Fig 1) has been used to produce the composite material along with carbon fiber. Jute fiber fabrics was collected from the local market to facilitate the fabrication of the composite material.

Epoxy LY556 was used as a matrix and Araldite HY951 was used as a hardener. The weight ratio of mixing epoxy and hardener was followed as per the supplier norms. Table 1 shows the properties of the jute and carbon fiber that have been used for the experiment.
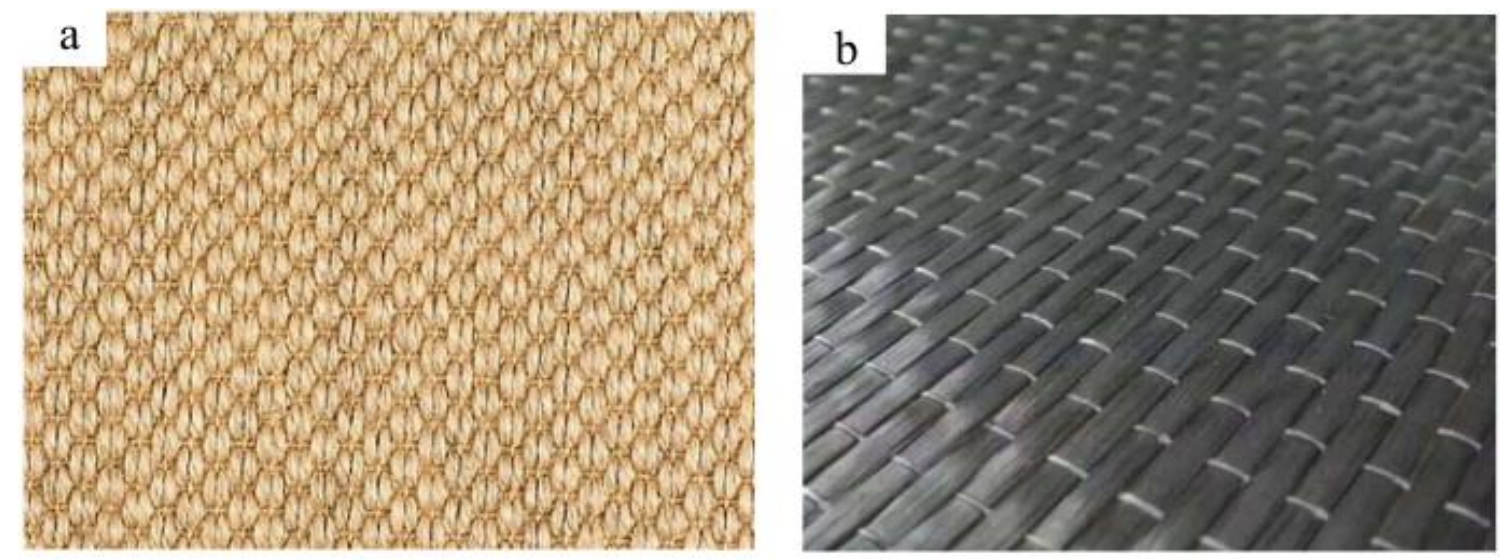

Figure 1 a) Jute fabric b) Carbon fabric

Table 1 Properties of Jute and Carbon fiber

\begin{tabular}{lccccc}
\hline \multicolumn{1}{c}{ Material } & $\begin{array}{c}\text { Areal } \\
\text { Density }\end{array}$ & $\begin{array}{c}\text { Weaving } \\
\text { pattern }\end{array}$ & $\begin{array}{c}\text { Tensile } \\
\text { strength }\end{array}$ & $\begin{array}{c}\text { Modulus of } \\
\text { elasticity }\end{array}$ & Thickness \\
\hline $\begin{array}{l}\text { Carbon } \\
\text { fiber }\end{array}$ & $300\left(\mathrm{~g} / \mathrm{m}^{2}\right)$ & Unidirectional & $3500 \mathrm{MPa}$ & $240 \mathrm{GPa}$ & $4.2 \mathrm{~mm}$ \\
\hline Jute fiber & $504\left(\mathrm{~g} / \mathrm{m}^{2}\right)$ & Unidirectional & $500 \mathrm{MPa}$ & $15 \mathrm{GPa}$ & $6.1 \mathrm{~mm}$ \\
\hline
\end{tabular}


The experiments were conducted in a Universal Testing Machine (SHIMADZU AGS$300 \mathrm{kNXD}$ ). The crosshead speed was $2 \mathrm{~mm} / \mathrm{min}$ for tensile and flexural test. To get an accurate result, five identical samples were tested, and the obtained result is shown in the bar chart in Fig. 3 and Fig. 4 for different stacking sequence of the composite with the error bar.

\subsection{Fabrication Procedure of Composite Laminates}

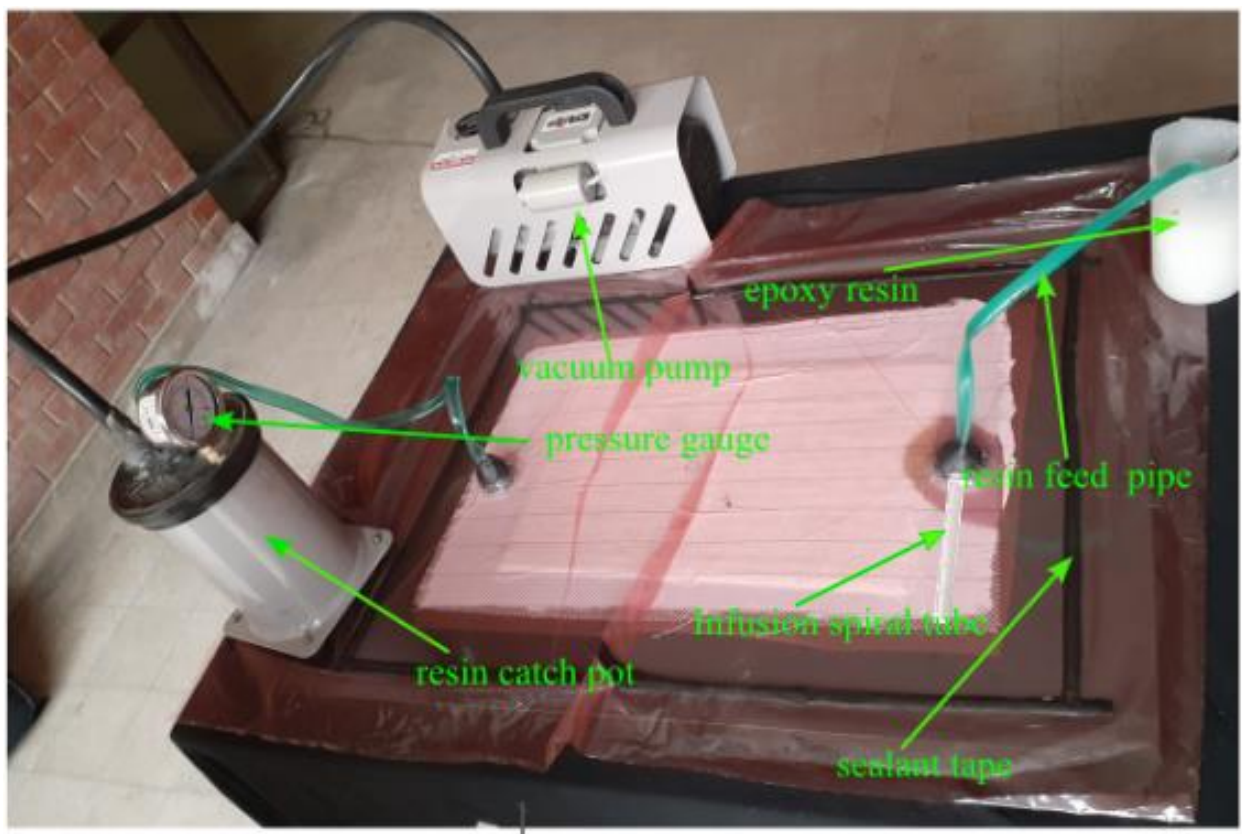

Figure 2 Experimental Setup

Vacuum-assisted resin infusion process in short VARI was used to fabricate the hybrid composite laminates. This process is widely accepted by the researcher as the produced composites have better mechanical properties in terms of strength, less void formation, and famous for manufacturing complicated structures compared to hand layup process. VARI process comprises of five steps (a) preparation of the mold and stacking of the fabric material; (b) mold sealing and vacuum creation; (c) epoxy resin preparation and degassing; (d) impregnation of resin and (e) curing of fabricated panels. Six (6) piles of jute and four (4) piles of carbon fiber have been used to assess the effect of stacking sequence on the tensile and flexural properties of composite material. In Fig. 2 a view of the experimental setup has been given.

The number of jute and carbon fiber layer was kept constant to determine the impact of the stacking sequence of the hybrid composites. After stacking the piles of jute and carbon fiber peel ply, infusion mesh and vacuum bagging film are used sequentially along with the sealant tape around the sample to facilitate the vacuum infusion process. Then the matrix was feed by the spiral pipe to the mold to start the infusion process. It took about 25-30 minutes to complete the infusion process. The vacuum chamber pressure was kept at -1.00 bar during the infusion process. The vacuum pump was supplied by the Easy Composite (ECVP425) from the United Kingdom. When the infusion process was done after that, the composites have been cured for 24 hours at room temperature. There was a total of $48.6 \%$ fiber content by weight in the entire sample. The percentage of jute fiber was $73 \%(\mathrm{w} / \mathrm{w})$ and carbon fiber $27 \%$ (w/w) Fig. 3 shows the five (5) different stacking sequences that have been used in this experiment. 

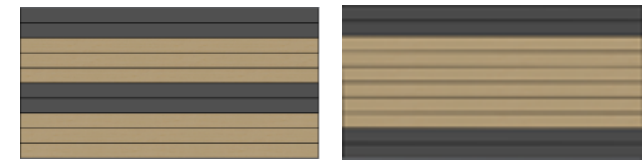

$\mathrm{S} 1=\mathrm{C}_{2} \mathrm{~J}_{3} \mathrm{C}_{2} \mathrm{~J}_{3}$

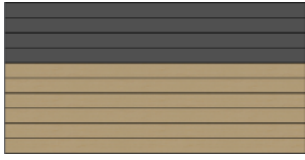

$\mathrm{S} 3=\mathrm{C}_{4} \mathrm{~J}_{6}$

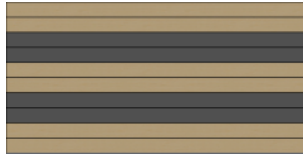

$\mathrm{S} 4=\mathrm{J}_{2} \mathrm{C}_{2} \mathrm{~J}_{2} \mathrm{C}_{2} \mathrm{~J}_{2}$

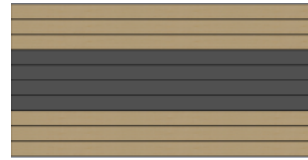

$\mathrm{S} 5=\mathrm{J}_{3} \mathrm{C}_{4} \mathrm{~J}_{3}$

Figure 3: Fiber stacking sequence for composite material $(\mathrm{C}=\mathrm{Carbon}=\mathrm{Jute}$ fiber $)$

\section{MECHANICAL TEST}

\subsection{Tensile Test}

Tensile specimens were prepared following ASTM D3039[18]. The dimension of the specimen has been illustrated in. The overall thickness was observed for all the composite was $6.8 \mathrm{~mm}$ with a variation of $0.2 \mathrm{mmm}$ and the gage length was $100 \mathrm{~mm}$ while testing the sample. The material was loaded in the universal testing machine then the load was applied at an increasing rate of $5 \mathrm{~mm} / \mathrm{min}$, until the breakage of the material has taken place. The load at this point is used to calculate the maximum tensile strength of the composite material. The experiment was repeated for five samples and the average values are used for the detailed analysis.

\subsection{Water Absorption Test}

The effect of water absorption on the manufactured hybrid composites were investigated in accordance with ASTM D 570 [19].Water absorption tests were conducted by immersing the composite specimens in a distilled water at $25^{\circ} \mathrm{C}$; until the samples reached near saturation. After immersion for 24 hours, the specimens were taken out from the water and all surface water was removed with a clean dry cloth and the specimens were weighed. This process was repeated regularly at $24,48,98,196$, and up to 312 hours exposure. The percentage of water absorption is obtained using the following equation.

Water absorption $(\%)=\frac{m_{2}-m_{1}}{m_{1}} \times 100$

Where $m_{1}$ is the weight before submerging in water $(\mathrm{g})$ and $m_{2}$ is the weight after submerging in water $(\mathrm{g})$. The percentage weight gain of the samples was measured at different time intervals and the moisture content versus square root of time was plotted.

\subsection{Numerical Simulation}

To validate the experimental data of the composite laminates numerical simulation has been carried out through Finite Element Analysis (FEA) using ANSYS R3 software. The static structural module and explicit dynamics module were used under static load and dynamic forces respectively. The FEA analysis were performed in three steps,

- Modelling and preprocessing: part modeling, assigning material properties, meshing and applying loads and boundary conditions

- Solving: Preparing and solving the linear equation of an element

- Post-Processing: Generating the results as graphs, tables or animations under different loads.

In the first step, a 3D geometry of the composite specimens was created with Solidworks software. Then the model was then imported to ANSYS. For the analysis of the composite material ACP tool was used. All the fabricated composites are considered to be orthotropic in nature and the material properties of the constituents are enlisted in Table 2. The values that have been enlisted in Table 2 are experiment value. 
Experimental and Numerical Investigation on the Tensile and Water Absorption Behavior of Jute/Carbon Reinforced Epoxy Composite

Table 2 Composite material properties for numerical simulation

\begin{tabular}{|c|c|c|}
\hline $\begin{array}{r}\text { Parameters } \\
\end{array}$ & Jute & Carbon \\
\hline Density $\rho\left(\mathrm{Kg} / \mathrm{m}^{3)}\right.$ & 1350 & 1500 \\
\hline Young's modulus $\mathrm{E}_{11}(\mathrm{GPa})$ & 22.5 & 45 \\
\hline Young's modulus E22 (GPa) & 0.95 & 44 \\
\hline Poisson's ratio $v_{12}$ & 0.35 & 0.3 \\
\hline Shear modulus $\mathrm{G}_{12}(\mathrm{GPa})$ & 0.41 & 5.2 \\
\hline
\end{tabular}

\section{RESULTS AND DISCUSSION}

\subsection{Tensile Behavior}

The bar chart that is represented in Fig 4 provides information about the tensile strength of the fabricated composite material. The stacking sequence of different fiber layers in the hybrid composite material has an insignificant effect on the tensile properties. From Fig 4 it can be observed that there is a slight variation in the UTS (ultimate tensile strength) among the four different stacking sequences. The highest UTS has been found for S1 sample which is 571 $\mathrm{MPa}$ and the lowest UTS has been observed for S5 sample (496 MPa) which is $13 \%$ lower than S1. The second largest UTS have been observed for S2 sample (548 MPa) which is just $4 \%$ lower than the highest UTS (S1).

The variation of tensile strength for the same fiber volume fraction may be attributed to the location of delamination and deboning inside the composite. Central placement of jute plies may split the carbon interaction and may increase the amount of deboning and delamination so that tensile strength plummeted with the rate of splitting. That is why, as the jute ply came close to the specimen surface, tensile strength improved.

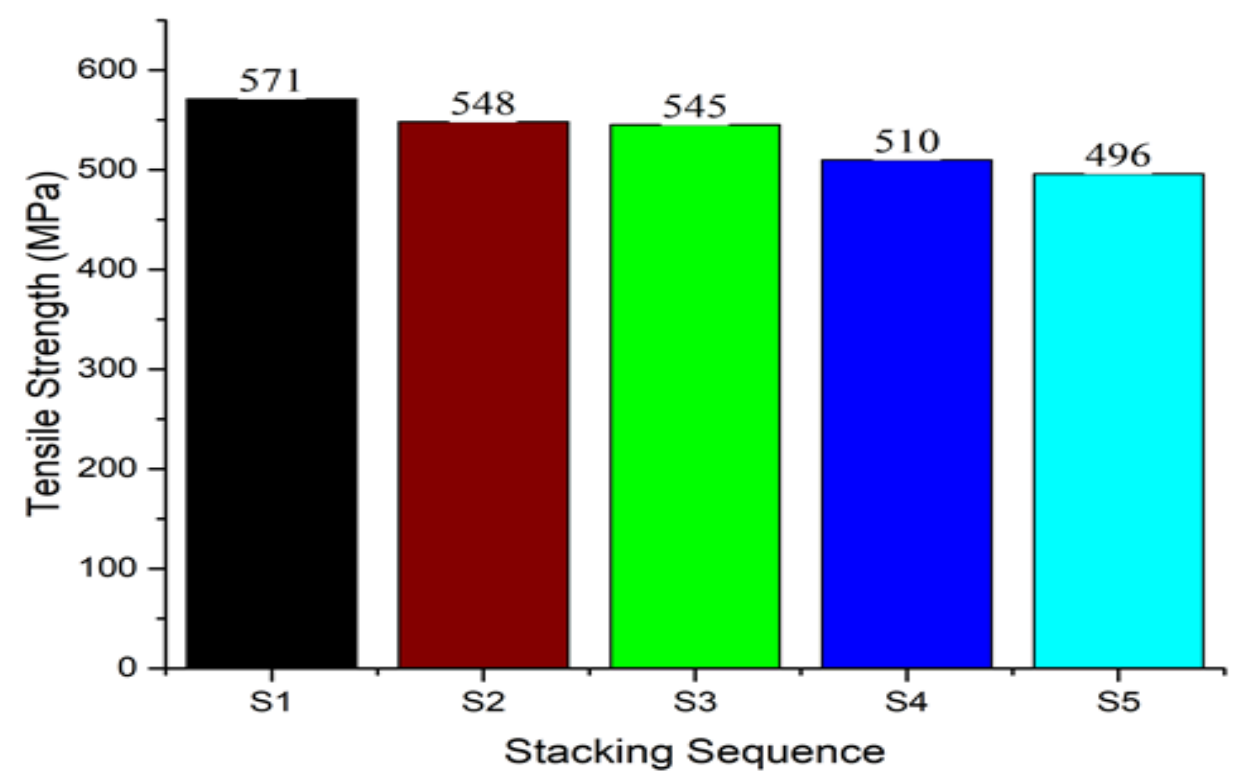

Figure 4 Influence of stacking patterns on Tensile strength of the hybrid jute/carbon laminates

It is also found that there is a sharp increase in the tensile strength (Fig 4) with the incorporation of jute fiber as core of the hybrid composite. The increase in the tensile strength is attributed to the reason that carbon fibers are stronger and stiffer than jute fiber. Hybridization of carbon fiber has provided the hybrid material much stiffer, stronger properties over its natural fiber counter parts, showing that the hybridization of carbon and jute can result in a material with significantly improved mechanical properties. 


\subsection{FEA Simulation Results of Flexural Strength}

The generated FEA model was validated by comparing the stress-strain curve of the composite laminates obtained from experimental and simulation of the tensile test. Figure 5 shows the experimental and FEA simulated tensile stress-strain diagrams of the laminates. It is clear that the stress-strain behavior of numerical results exhibited the similar trend of experimental findings. Also, the tensile stress found by the simulation was slightly higher than the experimental method. It may be due to the reason that during simulation the laminate was treated as homogeneous and there are no voids and no crack formation in the developed composites. But in reality, the laminates are non- homogeneous which resulted in presence of voids and occurrence of fiber matrix crack during experimental tensile test. Total deformation of the developed numerical models is illustrated in Fig 6.
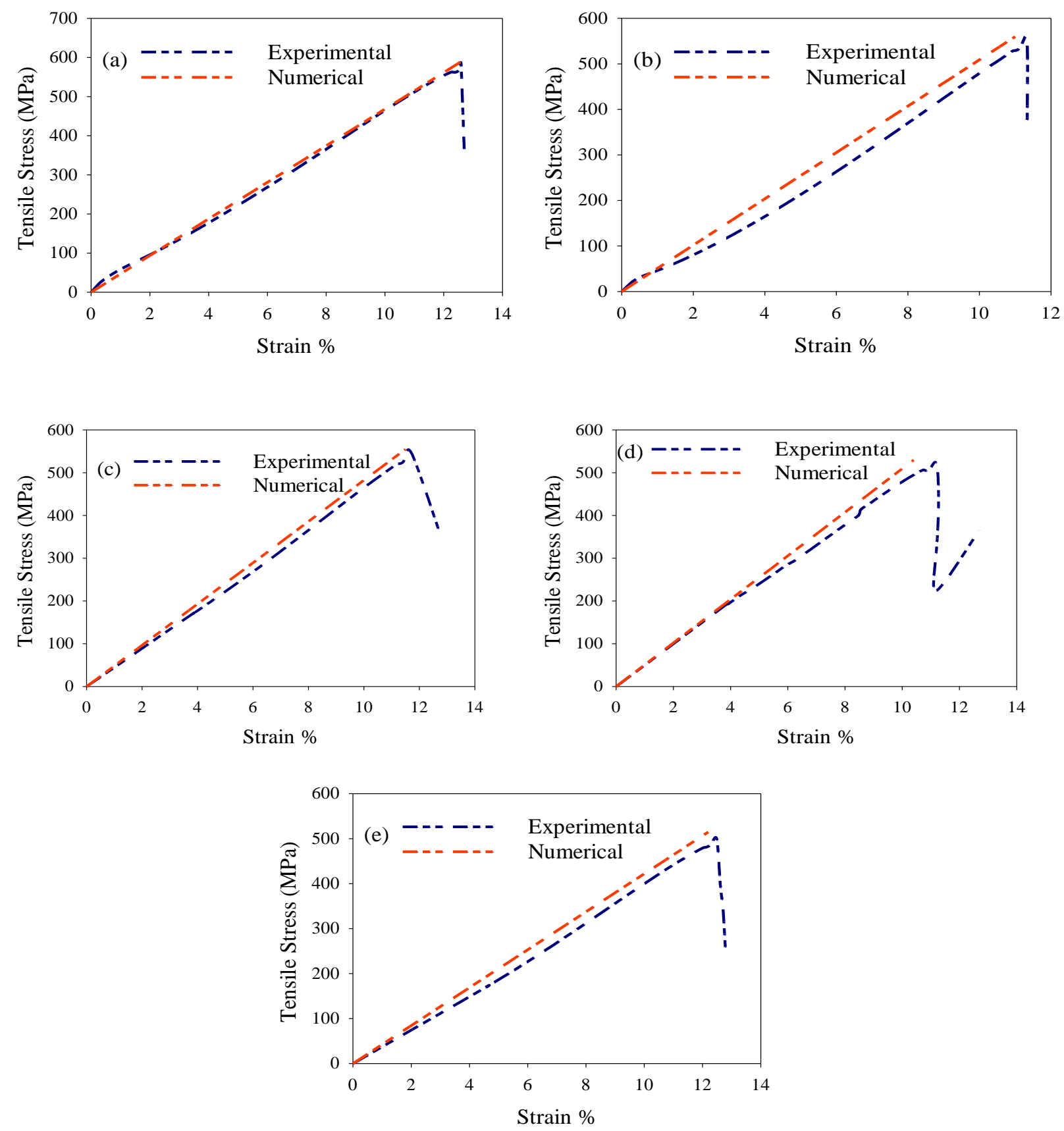

Figure 5 Experimental and FEA model of tensile stress vs strain (a) $S 1=C_{2} J_{3} C_{2} J_{3}$, (b)S2 $=C_{2} J_{6} C_{2}$, (c)S3 $=\mathrm{C}_{4} \mathrm{~J}_{6}$, (d) $\mathrm{S} 4=\mathrm{J}_{2} \mathrm{C}_{2} \mathrm{~J}_{2} \mathrm{C}_{2} \mathrm{~J}_{2},(\mathrm{e}) \mathrm{S} 5=\mathrm{J}_{3} \mathrm{C}_{4} \mathrm{~J}_{3}$. 

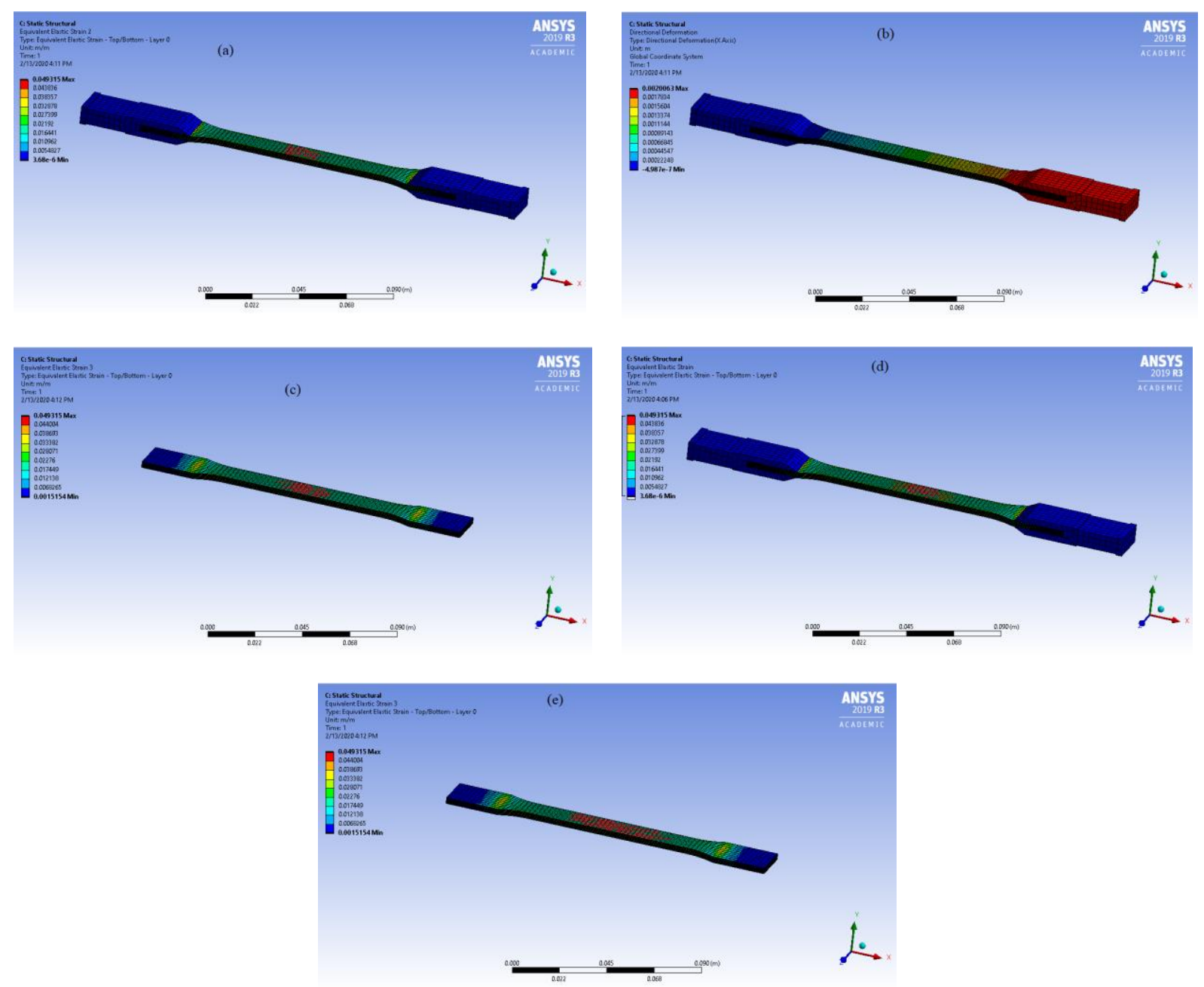

Figure 6 Total deformation after the under the tensile load (a) $S 1=C_{2} J_{3} C_{2} J_{3}$, (b)S2 $=C_{2} J_{6} C_{2}$, (c) $=$ $\mathrm{S} 3=\mathrm{C}_{4} \mathrm{~J}_{6},(\mathrm{~d})=\mathrm{S} 4=\mathrm{J}_{2} \mathrm{C}_{2} \mathrm{~J}_{2} \mathrm{C}_{2} \mathrm{~J}_{2},(\mathrm{e})=\mathrm{S} 5=\mathrm{J}_{3} \mathrm{C}_{4} \mathrm{~J}_{3}$.

\subsection{Water Absorption}

The moisture absorption by the samples was determined by the weight gain relative to the dry weight of the samples. The moisture content of each sample was computed using Eq. 1. The graph between the percentage of water absorption and square root of time in hours for carbon and jute-based epoxy hybrid composites is shown in Fig 7 for unidirectional composite laminates. the maximum amount of water absorbed by the hybrid composite material has been recorded continuously for 12 days (288 hours) after every 12 hours interval. 


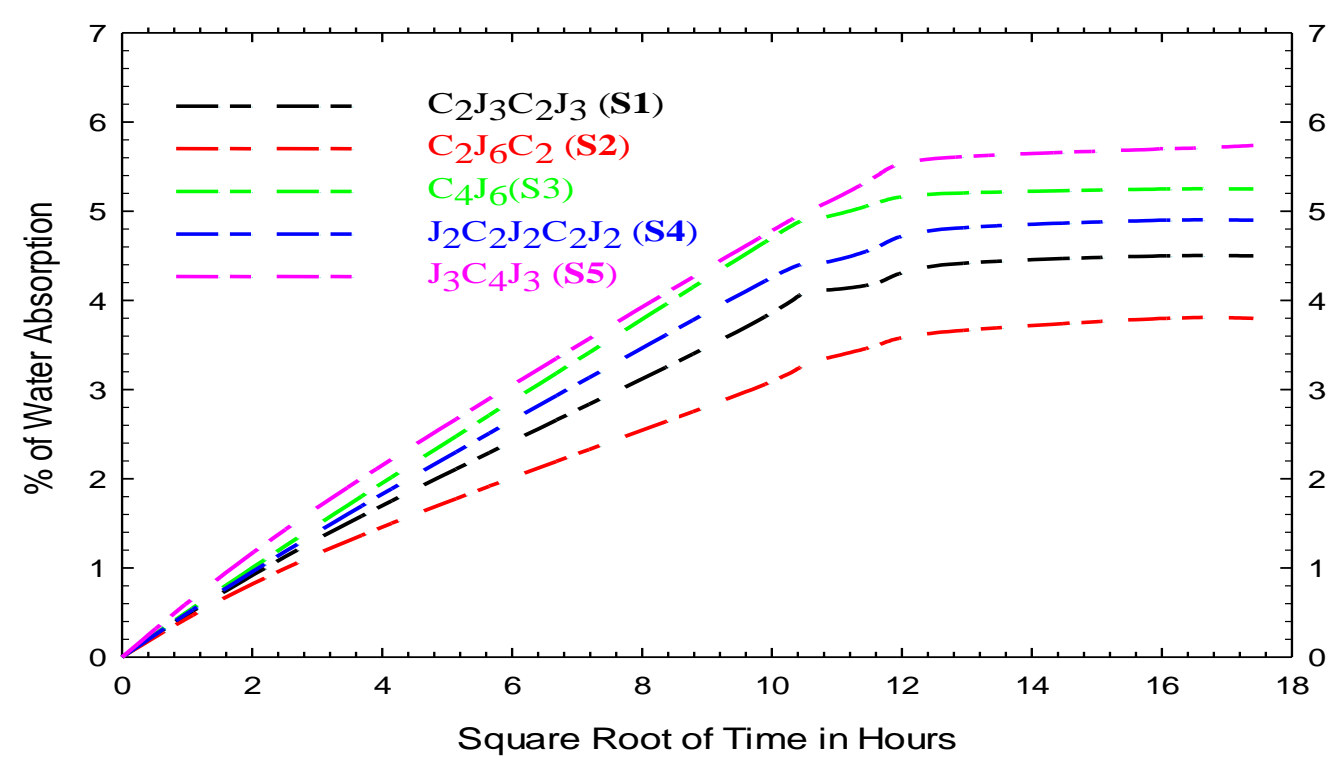

Figure 7 Water absorption curve for Unidirectional stacking sequence composites

It has been identified from the Fig 7 that each composite laminate absorbs water very promptly at the initial stage, then slows down and finally reaches a saturation stage. At the saturation stage, the maximum water uptake is shown by S5 followed by S3, S4, S1 and S2 (Fig 7). The maximum amount of water was observed by the S5 sample $5.73 \%$ and the minimum amount of water was absorbed by the S2 (3.8\%) sample. There is a slight variation in the percentage of water absorption among the composites.

When the jute fiber is exposed to water, the hydrophilic jute fibers start to absorb water leading to micro-cracking of the brittle thermosetting resin. Jute fibers have high cellulose content contributing to the diffusion of more water molecules at the interface by micro cracks. Then swelling of fibers occurs by the development of swelling stresses takes place, which results in the failure of the matrix. As soon as the matrix cracks, the capillary action of water molecules starts through micro cracks. Finally, debonding between fibers and matrix starts due to the attack of water molecules at fiber-matrix interfaces by capillarity action. In the case of hybrid jute/carbon composites, carbon fibers have negligible water absorption because of its hydrophobic nature. In hybrid jute/carbon composites, carbon fiber plays a role of barrier to prevent contact between jute fibers and water molecules. The hybrid composite having stacking sequence $\mathrm{C}_{2} \mathrm{~J}_{6} \mathrm{C}_{2}$ possesses the higher water resistance owing to the alternate positioning of layers of carbon fiber that strongly restricts the movement of water molecules into the composites. The hybrid composite with a stacking sequence $\mathrm{C}_{2} \mathrm{~J}_{3} \mathrm{C}_{2} \mathrm{~J}_{3}$ has an intermediate water uptake due to the presence of two carbon layers at bottom then three layers of jute followed by two layers of carbon fibers and three jute layers on the top, which allows diffusing of the water molecules from the jute layers. The hybrid composite $\mathrm{J}_{3} \mathrm{C}_{4} \mathrm{~J}_{3}$ possesses the lowest water resistance owing to 3 layers of jute fiber on the top and bottom side of the composite that makes it easier for water molecules to move into the layers of the composite which causes the highest amount of water absorption for all the composite laminates.

\section{CONCLUSION}

This experimental work was carried out to study the influences of layering patterns on the tensile and water absorption responses of jute/carbon fiber-based epoxy composites and the results were validated numerically for tensile specimen. 
Experimental and Numerical Investigation on the Tensile and Water Absorption Behavior of Jute/Carbon Reinforced Epoxy Composite

- Experimental results revealed that stacking sequence of the fiber layers have a significant influence on the mechanical properties of the composite material.

- The maximum amount of tensile strength was found for S1 sample which was 571 $\mathrm{MPa}$ and minimum amount of tensile strength was found for S5 (496 MPa).

- Numerical validations for the fabricated composites were performed by finite element analysis and closer rationality were observed between the results. The slighter deviation in the properties is due to the assumption that no void formation and proper bonding of fiber/matrix during FEA simulation of the composites.

- The combination $\left(\mathrm{C}_{2} \mathrm{~J}_{6} \mathrm{C}_{2}\right)$ would be suitable for critical applications which require high tensile strength and less water absorption property.

- The present experimental investigation of the jute/carbon epoxy composite fabrication leads to less weight and low-cost composite fabrication with reduced environmental impacts by lowering the carbon foot prints.

\section{REFERENCES}

[1] H. N. Dhakal, Z. Y. Zhang, R. Guthrie, J. MacMullen, and N. Bennett, "Development of flax/carbon fibre hybrid composites for enhanced properties," Carbohydrate Polymers, vol. 96, no. 1, pp. 1-8, 2013.

[2] S. Biswas, S. Shahinur, M. Hasan, and Q. Ahsan, "Physical, mechanical and thermal properties of jute and bamboo fiber reinforced unidirectional epoxy composites," Procedia Engineering, vol. 105, no. Icte 2014, pp. 933-939, 2015.

[3] V. Mishra and S. Biswas, "Physical and mechanical properties of bi-directional jute fiber epoxy composites," Procedia Engineering, vol. 51, no. NUiCONE 2012, pp. 561-566, 2013.

[4] M. Tehrani Dehkordi, H. Nosraty, M. M. Shokrieh, G. Minak, and D. Ghelli, "The influence of hybridization on impact damage behavior and residual compression strength of intraply basalt/nylon hybrid composites," Materials and Design, vol. 43, pp. 283-290, 2013.

[5] S. H. Han, H. J. Oh, H. C. Lee, and S. S. Kim, "The effect of post-processing of carbon fibers on the mechanical properties of epoxy-based composites," Composites Part B: Engineering, vol. 45, no. 1, pp. 172-177, 2013.

[6] R. Park and J. Jang, "Performance improvement of carbon fiber/polyethylene fiber hybrid composites," Journal of Materials Science, vol. 34, no. 12, pp. 2903-2910, 1999.

[7] K. L. Pickering and M. Institute of Materials, "Properties and performance of natural-fibre composites," Properties and Performance of Natural-Fibre Composites, pp. 542-555, 2008.

[8] F. L. Matthews and R. D. (Rees D. . Rawlings, Composite materials : engineering and science. CRC Press, 1999.

[9] P. Pantamanatsopa, W. Ariyawiriyanan, T. Meekeaw, R. Suthamyong, K. Arrub, and H. Hamada, "Effect of modified jute fiber on mechanical properties of Green rubber composite," Energy Procedia, vol. 56, no. C, pp. 641-647, 2014.

[10] S. MOHANTY, S. VERMA, and S. NAYAK, "Dynamic mechanical and thermal properties of MAPE treated jute/HDPE composites," Composites Science and Technology, vol. 66, no. 3-4, pp. 538-547, 2006. 
[11] M. R. Sanjay, G. R. Arpitha, and B. Yogesha, "Study on Mechanical Properties of Natural - Glass Fibre Reinforced Polymer Hybrid Composites: A Review," Materials Today: Proceedings, vol. 2, no. 4-5, pp. 2959-2967, 2015.

[12] E. Selver, P. Potluri, P. Hogg, and C. Soutis, "Impact damage tolerance of thermoset composites reinforced with hybrid commingled yarns," Composites Part B: Engineering, vol. 91, pp. 522-538, 2016.

[13] M. F. M. Alkbir, S. M. Sapuan, A. A. Nuraini, and M. R. Ishak, "Fibre properties and crashworthiness parameters of natural fibre-reinforced composite structure: A literature review," Composite Structures, vol. 148. pp. 59-73, 2016.

[14] M. Ramesh, K. Palanikumar, and K. H. Reddy, "Comparative Evaluation on Properties of Hybrid Glass Fiber- Sisal/Jute Reinforced Epoxy Composites," Procedia Engineering, vol. 51, pp. 745-750, 2013.

[15] Velu S and Srinivasan R, "Glass-Jute Fiber Reinforced Epoxy Composites," International Journal of Science and Research (IJSR) ISSN, pp. 1714-1720, 2013.

[16] R. Gujjala, S. Ojha, S. Acharya, and S. Pal, "Mechanical properties of woven jute-glass hybrid-reinforced epoxy composite," Journal of Composite Materials, vol. 48, no. 28, pp. 3445-3455, 2014.

[17] Y. Zhang, Y. Li, H. Ma, and T. Yu, "Tensile and interfacial properties of unidirectional flax/glass fiber reinforced hybrid composites," Composites Science and Technology, vol. 88, pp. 172-177, 2013.

[18] A. International and indexed, "Designation: D 3039/D 3039M - 00 Standard Test Method for Tensile Properties of Polymer Matrix Composite Materials 1," vol. 15, 2002.

[19] ASTM D570-98 (2018), "Standard Test for Water Absorption of Plastics," ASTM International. ASTM International, 2018. 